\title{
Parkinsonism as a Manifestation of Neuropsychiatric Systemic Lupus Erythematosus: A Case Report and Literature Review
}

\author{
Qi TANG, ${ }^{1}$ Jing WANG, ${ }^{2}$ Jinwei CHEN, ${ }^{1}$ Xi XIE, ${ }^{1}$ Jing TIAN $^{1}$ \\ ${ }^{1}$ Department of Rheumatology and Immunology, The Second Xiangya Hospital, Central South University, Changsha, China \\ ${ }^{2}$ Department of Rheumatology and Immunology, First People's Hospital Of Yunnan Province, Yunnan, China
}

\begin{abstract}
Involvement of the central nervous system in systemic lupus erythematosus has been well documented. Parkinsonism as a manifestation of central nervous system lupus is rare. In this article, we report a 17-year-old girl who developed parkinsonism within one month of the onset of systemic lupus erythematosus, and presented with expressionless facies, bradykinesia, marked rigidity, and hypermyotonia. Magnetic resonance imaging showed abnormity in bilateral basal ganglia, external capsule, insular lobe, and lateral hippocampus symmetrically. Methylprednisolone pulse therapy, intravenous cyclophosphamide, and intrathecal injection of methotrexate plus dexamethasone were prescribed. Two months later, the patient returned with complete clinical recovery of neuropsychiatric symptoms and signs.

Keywords: Cyclophosphamide; glucocorticoid; methotrexate; neuropsychiatric systemic lupus erythematosus; parkinsonism.
\end{abstract}

Systemic lupus erythematosus (SLE) is a chronic autoimmune disease. Neuropsychiatric systemic lupus erythematosus (NPSLE) is a subtype of SLE specifically involved in neurologic manifestations usually observed in central, peripheral, and autonomic nervous systems and sometimes with psychiatric disorders. ${ }^{1}$ Movement disorders such as chorea, ataxia, and hemiballismus have been described in the American College of Rheumatology classification of NPSLE. ${ }^{2}$ However, parkinsonism, as a movement disorder, is an extremely rare manifestation of NPSLE. Here, we report a patient of NPSLE with parkinsonism.

\section{CASE REPORT}

A 17-year-old girl was admitted to our hospital after one month of fever, hand erythema, and arthralgia. There were no significant findings in her personal or family history. Results from blood test showed leucopenia (white blood cell 2.7*10\%/L); positive antinuclear antibody (1:1000), anti-double stranded (ds) DNA, anti-Sjögren syndrome $\mathrm{A}$ antigen, anti-Sjögren syndrome $\mathrm{B}$ antigen, and anti-ribosome $\mathrm{P}$ protein; negative antiphospholipid antibody, anti-beta2GP1 antibody, and anti-neutrophil cytoplasmic antibodies (low complement $3(0.31 \mathrm{~g} / \mathrm{L})$ and high erythrocyte sedimentation rate $(89 \mathrm{~mm} / \mathrm{h})$. Urine test showed no hematuria or proteinuria. According to the 1982 revised criteria for the classification of SLE, she was diagnosed with SLE. The Systemic Lupus Erythematosus Disease Activity Index score was 16 . She was administered with intravenous methylprednisolone $(80 \mathrm{mg} /$ day, her weight was $50 \mathrm{~kg}$ ) for three consecutive days, followed by intravenous methylprednisolone (40 $\mathrm{mg} /$ day) and oral hydroxychloroquine (200 mg/day). Six days later, her temperature returned to normal, erythema almost disappeared, and arthralgia was significantly relieved. However,

Received: October 05, 2014 Accepted: March 14, 2015 Published online: June 13, 2015

Correspondence: Jing Tian, MD. Department of Rheumatology and Immunology, The Second Xiangya Hospital, Central South University, 410011 Changsha, China. Tel: +8613637312158 e-mail: yintianm@126.com

o2015 Turkish League Against Rheumatism. All rights reserved. 
during this one-week period, she developed a progressive slowdown of motor response, movement, thinking, speech, and reaction to stimuli. She did not complain of any limb weakness or numbness, giddiness, diplopia, tinnitus, urinary or bowel dysfunction. Neurological examinations showed that she was fully oriented with no evidence of cognitive dysfunction, aphasia, paresthesia, meningism, lateralizing neurological deficits, or cranial nerve palsies. With disease progression, she developed obvious expressionless face, bradykinesia, marked rigidity, and hypermyotonia in her extremities. She also had a festinating gait with only slight arm swing, and her gaits turned and started in hesitation but without rest or action tremor.

Head magnetic resonance imaging showed symmetrical long $T_{1}$ signal, slight long $T_{2}$ signal, and high $\mathrm{T}_{2}$ flair signal in bilateral basal ganglia, hippocampus, insular lobe, and subcortex of frontal gyrus rectus. Bilateral external capsule showed long $T_{1}$ signal, long $T_{2}$ signal, and high $\mathrm{T}_{2}$ flair signal (Figure 1). Enhanced magnetic resonance imaging showed a slightly increased signal intensity of bilateral basal ganglia. Lumbar puncture showed that the cerebrospinal fluid (CSF) was colorless and transparent with CSF pressure at $120 \mathrm{mmH}_{2} \mathrm{O}$. Biochemical test of CSF showed normal levels of protein $(175 \mathrm{mg} / \mathrm{L})$, glucose $(3.1 \mathrm{mmol} / \mathrm{L})$, lactate dehydrogenase, chloride, and adenosine deaminase, but a slight elevation of white blood cells $\left(25^{*} 10^{6} / \mathrm{L}\right)$. CSF smear, culture, Gram staining, acid-fast staining, tuberculosis DNA, virus antibody test, and fungal test were all negative. Autoantibodies to dsDNA and ribosomal $\mathrm{P}$ protein were positive in the CSF, but anti-phospholipid, anti-beta2GP1, antineuronal, anti-glial fibrillary acidic protein, antiendothelial cell, and anti-N-methyl-D-aspartate antibodies were negative. Since none of the drugs administered appeared to have potential side effect of parkinsonism and no other causes of parkinsonism could be recognized for this particular patient, she was considered to have NPSLE.

High dose intravenous methylprednisolone (500 mg/day) was prescribed for three days followed by oral prednisolone (1 $\mathrm{mg} / \mathrm{kg} / \mathrm{day}$ ), and intravenous cyclophosphamide $\left(600 \mathrm{mg} / \mathrm{m}^{2}\right.$ body surface
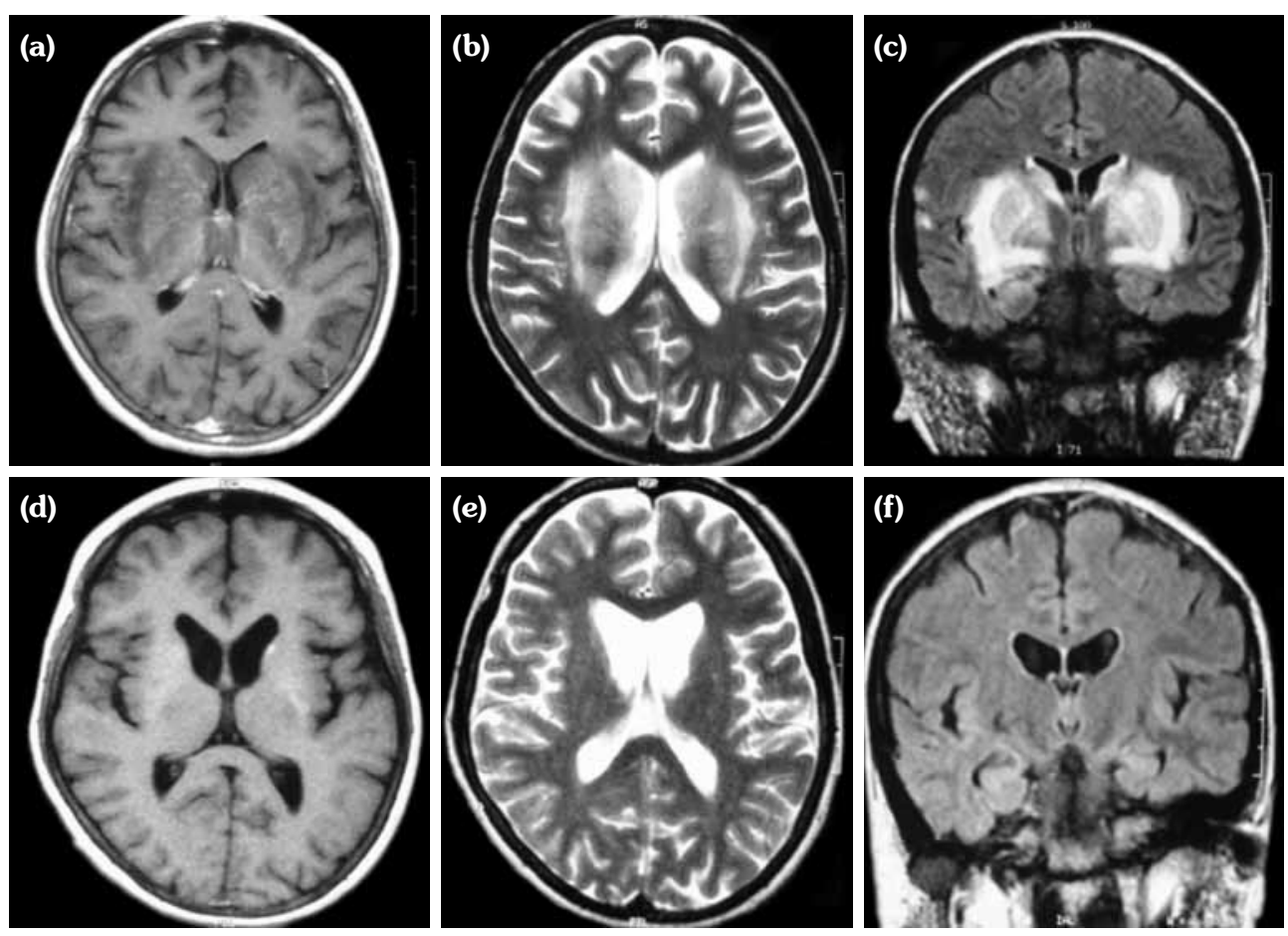

Figure 1. (a-c) Magnetic resonance imaging of the head showed symmetrical lesions in bilateral basal ganglia, hippocampus, insular lobe, and subcortex of frontal gyrus rectus. (d-f) Magnetic resonance imaging of the head was normal at patient's nine-month follow-up. 
area) was prescribed once. Intrathecal injection of methotrexate (MTX) (10 mg) and dexamethasone (DXM) (10 mg) were applied once a week for two weeks. After these treatments, the patient showed steady improvements in her gait, speech and movements. Two weeks later, her blood showed normal level of complement $3(0.84 \mathrm{~g} / \mathrm{L})$ and erythrocyte sedimentation rate $(18 \mathrm{~mm} / \mathrm{h})$. She was discharged on maintenance of oral prednisolone (30 $\mathrm{mg} / \mathrm{day})$, oral hydroxychloroquine (200 mg/day), and intravenous cyclophosphamide $(800 \mathrm{mg} / \mathrm{month})$. At the patient's two-month follow-up visit, we noticed that she had normal facial expression, speech, movement, and gait. Complement $3(0.86 \mathrm{~g} / \mathrm{L})$ and erythrocyte sedimentation rate $(12 \mathrm{~mm} / \mathrm{h})$ remained normal and the titer of antinuclear antibody decreased to 1:40. The Systemic Lupus Erythematosus Disease Activity Index was reevaluated with a score of 0 . Patient was still in remission at nine-month follow-up, and her head magnetic resonance imaging was normal (Figure 1).

\section{DISCUSSION}

Neuropsychiatric systemic lupus erythematosus associated parkinsonism was first described by Seminario and Pesano in $1930 .^{3}$ Since then, only about 30 NPSLE cases with parkinsonism have been reported to date (Table 1). ${ }^{3-19}$ Autoantibodies and immune-mediated vasculopathy was suggested in the pathogenesis of parkinsonism in NPSLE. ${ }^{20}$ Kunas et al. ${ }^{4}$ found antibodies to dopaminergic cells in serum from the NPSLE patients manifested with parkinsonism. They concluded that antidopamine antibodies could be specific to NPSLE patients with parkinsonism. However, to our knowledge, there are no controlled trials of any treatment for NPSLE with parkinsonism. Improvements have been reported in those patients treated with combination of steroids and cyclophosphamide, with or without antiparkinsonian drugs. ${ }^{10}$ In two cases, intravenous injection of immunoglobulins appeared to be effective after methylprednisolone and cyclophosphamide failed. ${ }^{11}$ Intrathecal injection of MTX plus DXM, which was assumed to enhance

Table 1. Summary of cases of reported neuropsychiatric systemic lupus erythematosus patients with parkinsonism

\begin{tabular}{|c|c|c|c|c|c|c|}
\hline Author & Age/gender & EEG & MRI & SPECT & Treatment & Outcome \\
\hline Seminario and Pessano ${ }^{3}$ & $17 / \mathrm{M}$ & $\mathrm{N}$ & $\mathrm{N}$ & $\mathrm{N}$ & $\mathrm{N}$ & Death \\
\hline Seminario and Pessano ${ }^{3}$ & $19 / \mathrm{F}$ & $\mathrm{N}$ & $\mathrm{N}$ & $\mathrm{N}$ & $\mathrm{N}$ & Death \\
\hline Seminario and Pessano ${ }^{3}$ & $30 / \mathrm{F}$ & $\mathrm{N}$ & $\mathrm{N}$ & $\mathrm{N}$ & $\mathrm{N}$ & Death \\
\hline Seminario and Pessano ${ }^{3}$ & $23 / F$ & $\mathrm{~N}$ & $\mathrm{~N}$ & $\mathrm{~N}$ & $\mathrm{~N}$ & Death \\
\hline Kunas et al. ${ }^{4}$ & $34 / F$ & $\mathrm{~N}$ & - & + & APD & Improvement \\
\hline Poch $^{5}$ & $21 / \mathrm{F}$ & $\mathrm{N}$ & $\mathrm{N}$ & $\mathrm{N}$ & $\mathrm{N}$ & $\mathrm{N}$ \\
\hline Poch $^{5}$ & $43 / \mathrm{F}$ & $\mathrm{N}$ & $\mathrm{N}$ & $\mathrm{N}$ & $\mathrm{N}$ & $\mathrm{N}$ \\
\hline Poch $^{5}$ & $27 / \mathrm{F}$ & $\mathrm{N}$ & $\mathrm{N}$ & $\mathrm{N}$ & G & Improvement \\
\hline Poch $^{5}$ & $28 / \mathrm{F}$ & $\mathrm{N}$ & $\mathrm{N}$ & $\mathrm{N}$ & $\mathrm{N}$ & $\mathrm{N}$ \\
\hline Willoughby et al. ${ }^{6}$ & $30 / \mathrm{M}$ & + & $\mathrm{N}$ & $\mathrm{N}$ & G & Death \\
\hline Yancey et al. $^{7}$ & $\mathrm{~N}$ & + & $\mathrm{N}$ & $\mathrm{N}$ & $\mathrm{N}$ & $\mathrm{N}$ \\
\hline Yancey et al. ${ }^{7}$ & $16 / \mathrm{F}$ & + & $\mathrm{N}$ & $\mathrm{N}$ & $\mathrm{N}$ & Improvement \\
\hline Nagaoka et al. ${ }^{8}$ & $35 / F$ & $\mathrm{~N}$ & $\mathrm{~N}$ & $\mathrm{~N}$ & $\mathrm{G}+\mathrm{APD}$ & Improvement \\
\hline García-Moreno and Chacón ${ }^{9}$ & $15 / F$ & - & - & $\mathrm{N}$ & APD+G+surgery & Improvement \\
\hline Khubchandani et al. ${ }^{10}$ & $12 / \mathrm{F}$ & + & + & + & $\mathrm{G}+\mathrm{Cy}+\mathrm{APD}$ & Recovery \\
\hline Kwong et al. ${ }^{11}$ & $9 / \mathrm{F}$ & + & + & + & $\mathrm{G}+\mathrm{Cy}+\mathrm{IgG}$ & Recovery \\
\hline Kwong et al. ${ }^{11}$ & $12 / \mathrm{F}$ & + & + & + & $\mathrm{G}+\mathrm{Cy}+\mathrm{IgG}$ & Recovery \\
\hline Shahar et al. ${ }^{12}$ & $15 / F$ & + & - & + & APD & Recovery \\
\hline Shahar et al. ${ }^{12}$ & $16 / \mathrm{F}$ & + & - & + & APD & Improvement \\
\hline Shahar et al. ${ }^{12}$ & $12 / \mathrm{F}$ & + & $\mathrm{N}$ & $\mathrm{N}$ & APD & $\mathrm{N}$ \\
\hline Miyoshi et al. ${ }^{13}$ & $42 / \mathrm{F}$ & - & - & $\mathrm{N}$ & $\mathrm{G}$ & Improvement \\
\hline Osawa et al. ${ }^{14}$ & $31 / \mathrm{F}$ & + & - & $\mathrm{N}$ & $\mathrm{G}+\mathrm{PP}+\mathrm{APD}+\mathrm{Cy}$ & Improvement \\
\hline Lim et al. ${ }^{15}$ & 24/M & $\mathrm{N}$ & + & $\mathrm{N}$ & $\mathrm{G}+\mathrm{Cy}$ & Improvement \\
\hline Chaco'n et al. ${ }^{16}$ & $16 / \mathrm{F}$ & - & - & $\mathrm{N}$ & APD & Improvement \\
\hline Tan et al. ${ }^{17}$ & $57 / F$ & $\mathrm{~N}$ & + & $\mathrm{N}$ & $\mathrm{G}+\mathrm{Cy}$ & Improvement \\
\hline Lee $\mathrm{PH}$ et al. ${ }^{18}$ & $43 / F$ & & - & + & G+APD & Recovery \\
\hline Orta Daniel and Ulises ${ }^{19}$ & $45 / \mathrm{F}$ & $\mathrm{N}$ & + & $\mathrm{N}$ & APD & Improvement \\
\hline Our case & $17 / F$ & $\mathrm{~N}$ & + & $\mathrm{N}$ & $\mathrm{G}+\mathrm{Cy}+\mathrm{IT}$ injection & Recovery \\
\hline
\end{tabular}


the immunosuppressive effects but reduce side effects, has been shown to improve the outcomes of NPSLE patients without parkinsonism. ${ }^{21}$ To our knowledge, our patient was the first NPSLE patient with parkinsonism reported to accept intrathecal injection of MTX plus DXM and obtain a satisfactory outcome. Although there was no control in our therapeutic regimen, results from this particular case support the notion that intrathecal injection of MTX and DXM, plus high dose intravenous methylprednisolone and cyclophosphamide for NPSLE patients with parkinsonism may be a plausible therapeutic strategy.

\section{Declaration of conflicting interests}

The authors declared no conflicts of interest with respect to the authorship and/or publication of this article.

\section{Funding}

The authors received no financial support for the research and/or authorship of this article.

\section{REFERENCES}

1. Bruns A, Meyer O. Neuropsychiatric manifestations of systemic lupus erythematosus. Joint Bone Spine 2006;73:639-45.

2. The American College of Rheumatology nomenclature and case definitions for neuropsychiatric lupus syndromes. Arthritis Rheum 1999;42:599-608.

3. Seminario C, Pesano J. Cuatro casos clinicos de lupus eritematoso agudo. Sem Med (B Air) 1930;2:721-30.

4. Kunas RC, McRae A, Kesselring J, Villiger PM. Antidopaminergic antibodies in a patient with a complex autoimmune disorder and rapidly progressing Parkinson's disease. J Allergy Clin Immunol 1995;96:688-90.

5. Poch GF. Enfermedades del colágeno. Manifestaciones neurológicas, musculares y psiquiátricas. Buenos Aires: López Libreros Editores SRL; 1960.

6. Willoughby EO, Cardon L, Rubnitz ME. Clinicopathological conference: psychotic episodes, meningitis, and chest pain. Postgrad Med 1964;35:318-26.

7. Yancey CL, Doughty RD, Athreya BH. Central nervous system involvement in childhood systemic lupus erythematosus. Arthritis Rheum
1981;24:1389-5.

8. Nagaoka $\mathrm{S}$, Kato $\mathrm{K}$, Ishigatsubo $\mathrm{Y}$, Chiba J, Sakamoto H, Nose K, et al. A case of systemic lupus erythematosus with akinesia, muscle rigidity and neurogenic bladder. Ryumachi 1984;24:382-8.

9. García-Moreno JM, Chacón J. Mov Disord 2002;17:1329-35.

10. Khubchandani RP, Viswanathan V, Desai J. Unusual neurologic manifestations (I): Parkinsonism in juvenile SLE. Lupus 2007;16:572-5.

11. Kwong KL, Chu R, Wong SN. Parkinsonism as unusual neurological complication in childhood systemic lupus erythematosus. Lupus 2000;9:474-7.

12. Shahar E, Goshen E, Tauber Z, Lahat E. Parkinsonian syndrome complicating systemic lupus erythematosus. Pediatr Neurol 1998;18:456-8.

13. Miyoshi Y, Atsumi T, Kitagawa H, Ogura N, Amasaki $\mathrm{Y}$, Tsutsumi A, et al. Parkinson-like symptoms as a manifestation of systemic lupus erythematosus. Lupus 1993;2:199-201.

14. Osawa H, Yamabe H, Kaizuka M, Tamura N, Tsunoda $\mathrm{S}$, Shirato KI, et al. Systemic lupus erythematosus associated with transverse myelitis and parkinsonian symptoms. Lupus 1997;6:613-5.

15. Lim SM, Oldfield M, Abbott RJ. Systemic lupus erythematosus presenting with steroid-responsive parkinsonism and post-hemiplegic dystonia. Eur $\mathrm{J}$ Neurol 1998;5:309-312.

16. Chacón J, García-Moreno JM, Valencia J, Redondo $\mathrm{L}$, Alegre S, Castro A, et al. Parkinson disease of juvenile onset with systemic lupus erythematosus in a pre-symptomatic stage. Rev Neurol 1999;29:725-7. [Abstract]

17. Tan EK, Chan LL, Auchus AP. Reversible parkinsonism in systemic lupus erythematosus. J Neurol Sci 2001;193:53-7.

18. Lee PH, Joo US, Bang OY, Seo CH. Basal ganglia hyperperfusion in a patient with systemic lupus erythematosus-related parkinsonism. Neurology 2004;63:395-6.

19. Orta Daniel SJ, Ulises RO. Stroke of the substance nigra and parkinsonism as first manifestation of systemic lupus erythematosus. Parkinsonism Relat Disord 2008;14:367-9.

20. EfthimiouP, Blanco M. Pathogenesis of neuropsychiatric systemic lupus erythematosus and potential biomarkers. Mod Rheumatol 2009;19:457-68.

21. Valesini G, Priori R, Francia A, Balestrieri G, Tincani A, Airo $P$, et al. Central nervous system involvement in systemic lupus erythematosus: a new therapeutic approach with intrathecal dexamethasone and methotrexate. Springer Semin Immunopathol 1994;16:313-21. 